\title{
Vacunación de pacientes adultos receptores de trasplante de células madre hematopoyéticas. Perspectiva de Costa Rica
}

\author{
M. del Rosario Espinoza Mora, Gustavo Lazo Páez, M. Paz León Bratti y Christian Schauer
}

\section{Vaccination of adult patients receiving hematopoietic stem cell transplantation. Perspective of Costa Rica}

In this article the present recommendations for immunization of adult patients who received hematopoietic stem cell transplantation -a common procedure in therapy of many types of hematological diseases and serious inborn defects of the immune system- are reviewed and discussed. Patients that undergo this kind of transplantation procedure exhibit, compared to the general population, an elevated susceptibility of immune-preventable infections, due to loss of the humoral and cellular protective immunity. A revaccination strategy for transplanted patients can result in a significant diminution of morbidity and mortality related to the treatment of these diseases. Few data are published about the duration and magnitude of the vaccination response in this specific population of patients. Moreover, deviation from international guidelines recommendations for post-transplant immune prophylaxis can be observed frequently, partly as a result of the absence of specific vaccines in some countries. Multiple factors as intensity of the pharmacologic immune suppression, myeloablative regimen, administration of monoclonal and polyclonal antibodies, duration of the post-transplant period or the presence of graft-versus-host disease (GVHD), can influence the immune response and establish special considerations for certain biological agents, as observed in case of living attenuated virus composed vaccines. This conditions are responsible for the fact that an optimal time point for vaccination of transplanted patients remains not clearly defined. More specific studies about the underlying immunological mechanisms during immunocompromised periods are necessary to understand better the immunogenicity and security of existing vaccines. The development of innovative vaccines as well can induce certain advances in the post-transplant therapy.

Key words: Hematopoietic stem cell transplantation, cellular immunity, immunodeficiency, immunogenicity, immune suppression, vaccine.

Palabras clave: Trasplante de células madre hematopoyéticas, inmunidad celular, inmunodeficiencia, inmunogenicidad, inmunosupresión, vacuna.

\section{Consideraciones generales acerca del} trasplante de células madre hematopoyéticas

$\mathrm{E}$ 1 trasplante de células hematopoyéticas consiste en la transferencia de estas células de un individuo a otro (trasplante alogénico) o el retorno de células colectadas de un individuo a sí mismo (trasplante autólogo), posterior a la manipulación de las células y del receptor. El objetivo del trasplante es la implantación permanente de las células administradas para inducir la reconstitución del sistema linfohematopoyético en el receptor. El injerto completo del donante o quimerismo completo, en que el sistema hematopoyético del receptor es sustituido totalmente por la progenie del trasplante, es la meta de muchos protocolos para asegurar la máxima actividad del injerto contra las células neoplásicas (graftversus-tumor (GVT) activity) en los pacientes con enfer- medades malignas ${ }^{1}$. En otros contextos clínicos en cambio (por ej.: síndromes de falla medular, inmunodeficiencias congénitas, deficiencias enzimáticas y hemoglobinopatías), un estado de quimerismo mixto donde células madre del donante y del receptor sobreviven y coexisten, es suficiente para curar la condición subyacente ${ }^{2}$.

\section{Reconstitución inmunológica posterior al trasplante de células madre hematopoyéticas}

Las células hematopoyéticas utilizadas en el trasplante pueden derivarse de médula ósea, sangre periférica o sangre de cordón umbilical. La reconstitución del sistema inmunológico en este tipo de procedimientos está condicionada por múltiples factores como el origen de las células hematopoyéticas (autólogo, alogénico o de
Hospital Rafael Ángel Calderón Guardia, San José, Costa Rica. Servicio de Medicina Interna e Inmunología (MRE). Hospital Nacional de Niños, San José, Costa Rica. Servicio de Inmunología Pediátrica (GL). Hospital México, San José, Costa Rica.

División de Inmunología Clínica (MPL).

Universidad Latinoamericana de Ciencia y Tecnología, San José, Costa Rica (CS).

No existió financiamiento externo. Los autores declaran no presentar conflictos de interés en la realización de la revisión.

Recibido: 30 de noviembre de 2015 Aceptado: 10 de octubre de 2016

Correspondencia a: María del Rosario Espinoza Mora rosasur@gmail.com 
cordón umbilical), la quimioterapia de acondicionamiento utilizada, los fármacos empleados como profilaxis para la enfermedad injerto contra hospedero (graft versus host disease, GVHD), en especial la inmunoglobulina anti-linfocítica, la existencia de GVHD y la aparición de infecciones oportunistas durante el período de recuperación hematológica ${ }^{3,4}$. Este proceso varía de paciente a paciente en el rango de semanas a meses y se correlaciona con la reactivación de infecciones virales latentes (como citomegalovirus) e infecciones micóticas, así como de recaídas de la malignidad a consecuencia de la profunda inmunosupresión ${ }^{5}$. La GVHD crónica, además se asocia con inmunodeficiencias celulares y humorales que incluyen falla macrofágica, impedimento de quimiotaxis y respuesta pobre a vacunaciones ${ }^{6-8}$.

El establecimiento del injerto se define como el punto en el cual un paciente puede mantener un número absoluto de neutrófilos $>500 / \mathrm{mm}^{3}$ y un recuento sostenido de trombocitos $>20.000 / \mathrm{mm}^{3}$ por más de tres días consecutivos, sin requerimiento transfusional. En el trasplante alogénico, la media es de 22 días después del procedimiento, con un rango que oscila entre 6 y 84 días. En ausencia de terapia corticoesteroidal, el injerto se asocia con la restauración de una función fagocítica efectiva que resulta en la disminución del riesgo de infecciones micóticas y bacterianas (Tabla 1) ${ }^{9-11}$. La recuperación de los leucocitos polimorfonucleares se inicia aproximadamente a las dos semanas en el caso de que se hayan empleado células hematopoyéticas movilizadas con factor estimulante de colonias granulocíticas (G-CSF) y obtenidas por aféresis, a las tres semanas posterior al injerto de médula ósea y a las cuatro semanas en caso de células de cordón umbilical ${ }^{12-15}$

El proceso de reconstitución inmunológica se inicia con la resurgencia de la inmunidad innata en las primeras semanas post trasplante, seguida de la recuperación cuantitativa y cualitativa del sistema inmune adaptativo, lo cual suele abarcar un período promedio de dos años, con un rango relacionado con los condicionantes anteriormente mencionados ${ }^{16-18}$. La aparición de granulocitos, monocitos, células dendríticas y linfocitos NK en sangre periférica marca el inicio de la recuperación celular, lo que sucede dos a tres semanas post-trasplante según el régimen de acondicionamiento y la fuente de injerto utilizados. Esto puede verse favorecido por el uso de G-CSF, que puede influenciar una mejoría, tanto en el recuento como en la función celular ${ }^{19,20}$.

Las células NK constituyen la primera subpoblación linfocitaria en aparecer en sangre periférica, usualmente a los seis meses del trasplante y muestran una rápida recuperación funcional ${ }^{21,22}$. El restablecimiento de las células NK es seguido por el de células T CD $8^{+}$, células B y finalmente células $\mathrm{T} \mathrm{CD} 4^{+23-25}$. Las células $\mathrm{B}$ tienen una recuperación cuantitativa alrededor de los tres meses postinfusión, aunque su función replicativa y diferenciativa probablemente sea efectiva entre seis y 12 meses después del procedimiento. El compartimiento de células B de memoria es el último de esta población en regenerarse, siendo más rápido el proceso en el injerto de células madre de cordón umbilical ${ }^{15,16,26,27}$. Durante las primeras semanas post-trasplante, se observa una fase inicial de expansión periférica de células $\mathrm{T}$ provenientes de los clones infundidos con el injerto e independiente del timo, que genera un compartimento con repertorio limitado. Posteriormente acontece una fase de recuperación donde las células T naif provenientes de los precursores hematopoyéticos siguen la ruta de linfopoyesis tímica tradicional, que resulta en un repertorio más amplio y funcional. Este proceso será aceptable, sin embargo, hasta transcurridos dos a tres años después. Las diferencias observadas en el escenario individual estarán dadas por la edad (correlacionable con un timo atrófico en el paciente de mayor edad), la presencia de GVHD, la terapia preventiva de esta enfermedad y la fuente del injerto, entre otros factores. Alrededor de 25\% de los pacientes muestran células $\mathrm{T}$ funcionales a los tres meses post-trasplante, lo que demanda un desafío médico en el seguimiento de la reconstitución ${ }^{28-30}$.

El restablecimiento de la inmunidad adaptativa posterior al trasplante hematopoyético sigue, por tanto, un prolongado e ineficiente proceso en el cual los déficits inmunológicos persisten por años después del procedimiento, principalmente si éste fue de carácter alogénico $^{26,28,31}$. Por ejemplo, aunque los receptores de trasplante alogénico puedan alcanzar recuentos linfocitarios

Tabla 1. Fases de reconstitución inmunológica post-trasplante de progenitores hematopoyéticos

Fase 1: Pre-implantación

Neutropenia profunda, incompetencia de barreras epiteliales (mucositis, catéteres percutáneos)

Del día 0 al día 15-45
Fase 2: Post-implantación

Inmunodeficiencia celular y humoral, recuperación inicial de células NK, incremento de células T CD8 ${ }^{+}$ limitado repertorio de células $T$

Del día 15-45 al día 100
Fase 3: Fase tardía

Inmadurez de la inmunidad celular y humoral, recuperación del número y función de células $\mathrm{B}$ y $\mathrm{T}$, recuperación lenta de la diversidad del repertorio

Del día 100 en adelante

Adaptado de: 25,44 
normales a las ocho semanas del trasplante, exhiben por lo general relaciones CD4/CD8 anormales, con aumento en las células $\mathrm{T} \mathrm{CD}^{+}$en relación con las células T CD4 ${ }^{+}$, condición que puede persistir por varios años ${ }^{10,25,32}$. Estos pacientes pueden además mostrar deficiencias persistentes de inmunoglobulinas ( $\mathrm{Ig}$ ), como $\operatorname{IgG}_{2}, \mathrm{IgG}_{4}$ e $\operatorname{IgA}$ después del trasplante y experimentar dificultades para el cambio de isotipo de IgM a IgG tras la exposición antigénica ${ }^{20,31}$.

\section{Evaluación del momento óptimo de inicio de la vacunación en pacientes receptores de trasplante}

Todo paciente receptor de trasplante de células madre hematopoyéticas debe ser considerado como un individuo "nunca antes vacunado", pues la restauración completa de la competencia inmune humoral posterior al trasplante requiere de la restitución de los linfocitos $\mathrm{B}$ de memoria, que ocurre como resultado de la exposición a antígenos ambientales, vaccinales o provenientes de patógenos comunes y es dependiente de la cooperación de los linfocitos T CD4 ${ }^{+}$. Por consiguiente, la normalización del número de células $\mathrm{B}$ en los primeros seis meses posteriores al trasplante no garantiza una reconstitución completa de la competencia humoral adaptativa ${ }^{20}$.

La única manera de estimar la competencia inmune humoral posterior al trasplante es mediante la documentación de aumentos clínicamente significativos de anticuerpos específicos después de las inmunizaciones o infecciones. La aplicación de una vacuna con ulterior medición de anticuerpos específicos se conoce como reto inmunológico o inmunización diagnóstica, la cual ofrece muchas ventajas en la determinación de la competencia inmunitaria pues permite evaluar el grado de respuesta adaptativa in vivo de cada paciente en particular y tiene mayor validez que los análisis in vitro de función celular. Para su realización se emplean principalmente las reacciones contra antígenos contenidos en vacunas inactivadas, utilizadas para el diagnóstico y clasificación de las inmunodeficiencias primarias y en la estratificación del grado de inmunocompromiso en pacientes con terapia inmunosupresora prolongada ${ }^{33-35}$. Idealmente, los anticuerpos contra antígenos vacunales deberían medirse antes y después de la inmunización para determinar sus niveles basales y post-vacunación, lo que también puede orientar a justificar el requerimiento de dosis de refuerzo ${ }^{36}$. Los anticuerpos que se determinan más comúnmente en estas reacciones son contra antígenos proteicos de sarampión, rubéola, difteria, tétanos y hepatitis B, y contra antígenos polisacáridos de Streptococcus pneumoniae y Haemophilus influenzae, contenidos en las vacunas recomendadas $^{34,37}$. En individuos sanos, las respuestas secundarias a antígenos proteicos de tétanos y difteria son robustas y pueden ser fácilmente determinadas mediante inmunoensayo ligado a enzima (ELISA). En general, la respuesta a tétanos es mejor que a difteria, posterior a la aplicación de la vacuna Td del adulto. De esta forma, la magnitud de la producción específica de anticuerpos en este caso provee una evaluación bastante fidedigna de la función inmunológica adaptativa ${ }^{35}$. El análisis de la inmunidad independiente de células $\mathrm{T}$ es en cambio más complicado porque la interpretación de la respuesta contra antígenos polisacáridos de $H$. influenzae y $S$. pneumoniae no se halla estandarizada aún y puede estar influenciada por la edad del paciente y la presencia de títulos pre-existentes de anticuerpos por vacunación previa, exposición bacteriana anterior o colonización nasofaríngea ${ }^{38-40}$.

\section{Principios básicos de las inmunizaciones en el contexto del trasplante de células madre hematopoyéticas}

Antes de decidir inmunizar a un paciente receptor de trasplante es importante tomar en cuenta los siguientes principios básicos:

1. Virtualmente todos los receptores de trasplante hematopoyético pierden irreversiblemente la memoria inmunológica acumulada durante la vida, después del acondicionamiento medular. Debido a que la transferencia de inmunidad del donador al receptor es variable y se halla influenciada por el momento de exposición antigénica de ambos, la inmunización pasiva adquirida del donante no provee al receptor de una inmunidad persistente contra enfermedades infecciosas ${ }^{41}$.

2. Aunque la inmuno-reconstitución posterior al trasplante autólogo de progenitores hematopoyéticos es más rápida que tras el alogénico, los mecanismos de pérdida de la inmunidad en ambos procesos parecen ser similares, por lo que se recomienda emplear los mismos regímenes de inmunización ${ }^{42-44}$.

3. Para que una vacuna ocasione una respuesta clínica significativa, la inmunidad del paciente debe estar al menos parcialmente reconstituida. Al considerarse como nunca antes inmunizados, los receptores de trasplante deben recibir, idealmente, las vacunas más inmunogénicas que se encuentren disponibles para garantizar la máxima protección ${ }^{44}$.

4. En general, células $\mathrm{T}$ capaces de responder a nuevos antígenos se generan seis a 12 meses posttrasplante, más tardíamente en adultos que en niños. Las primeras células de la inmunidad adaptativa en expandirse después del trasplante son los linfocitos $\mathrm{T}$ de memoria, lo cual confiere a las vacunas conjugadas una mayor ventaja protectora en esta población de 
pacientes. En consecuencia, la inmunización con vacunas inactivadas en los primeros meses del trasplante está ampliamente recomendada y puede empezarse a los seis meses del procedimiento, con un inicio más temprano en el caso de la vacuna inactivada contra influenza (a los cuatro meses del trasplante) y de la vacuna conjugada contra Streptococcus pneumoniae (a los tres meses del trasplante) ${ }^{45}$.

5. La cronología de la vacunación puede ser adaptada a la competencia inmunitaria del paciente, la que según el criterio de los autores de esta revisión, puede evaluarse mediante parámetros comúnmente empleados en el abordaje diagnóstico inicial de las inmunodeficiencias y en la evaluación de inmunizaciones en pacientes inmunocomprometidos (Tabla 2) $34,46-48$.

6. La inmunización con agentes infecciosos vivos atenuados en pacientes inmunocomprometidos puede ocasionar reactivación de las cepas contenidas en la vacuna. No obstante, ante la carencia de alternativas inactivadas para ciertos agentes infecciosos, los estudios en inmunización con vacunas vivas posterior al trasplante se han incrementado en los últimos años ${ }^{49}$. La recomendación actual de administración de vacunas que contienen virus atenuados de influenza (LAIV), sarampión, rubéola, parotiditis, fiebre amarilla y varicela zoster por lo general solamente se considera si el paciente:

- Ha cumplido al menos 24 meses post trasplante.

- Presenta reconstitución inmunitaria completa.
- No se halla bajo inmunosupresión farmacológica.

- No cursa con GVHD y

- No se encuentra en período de gestación ${ }^{45,50,51}$.

7. Los criterios de competencia inmunitaria para indicación de vacunas con microorganismos vivos son semejantes a los empleados para la aplicación de vacunas inactivadas (Tabla 2), aunque para asegurar el mayor beneficio de la vacunación sin perjuicio del paciente, se requiere la presencia de todos los criterios. Con todo, en aquellos pacientes con compromiso inmunitario celular que muestren respuestas humorales adecuadas frente a antígenos proteicos, podrían indicarse en determinados casos vacunas vivas posterior a la evaluación por parte de un inmunólogo, siempre y cuando el beneficio potencial exceda los riesgos estimados ${ }^{46}$.

8. Siempre que sea posible, se debe documentar la seroconversión posterior a la aplicación de una vacuna. Es decir, un aumento de al menos cuatro veces en los títulos de anticuerpos específicos con posterioridad a la exposición a un agente infeccioso, ya sea natural o vacunal. La ausencia de seroconversión denota una respuesta vacunal sub-óptima y obliga a considerar la aplicación de dosis adicionales de la vacuna ${ }^{35,52}$.

9. A diferencia de la seroconversión, la seroprotección involucra el establecimiento de una concentración predefinida de anticuerpos (o punto de corte) en el que se asume que la probabilidad de protección clínica es de $50 \%$ en caso de exposición al agente infeccioso. Sin embargo, la ausencia de títulos protectores de an-

Tabla 2. Criterios sugeridos para la evaluación de inmunocompetencia en pacientes receptores de trasplante hematopoyético

$\begin{array}{lll}\text { Criterios Análisis Metas } & \text { Metas }\end{array}$

Recuentos normales Citometría de flujo

de linfocitos T

Linfocitos T CD3 $\geq 1.400 / \mathrm{mm}^{3}$ en pacientes de 12 a 17 años $y \geq 960 / \mathrm{mm}^{3}$ en mayores de 18 años

Linfocitos T CD4 $\geq 700 / \mathrm{mm}^{3}$ en pacientes de 12 a 17 años y $>540 / \mathrm{mm}^{3}$ en mayores de 18 años

\begin{tabular}{|c|c|c|}
\hline $\begin{array}{l}\text { Funcionalidad de } \\
\text { células T }\end{array}$ & Estimulación in vitro con mitógenos de células T & $\begin{array}{l}\text { Proliferación a mitógenos > } 2 \text { DS o 50\% del valor control } \\
\text { Título de lgG específica post-vacunación (o infección natural) } 4 \text { veces el valor basal }\end{array}$ \\
\hline $\begin{array}{l}\text { Producción normal de } \\
\text { inmunoglobulinas }\end{array}$ & $\begin{array}{l}\text { Inmunoensayo para IgG específica a antígenos } \\
\text { proteicos T-dependientes (toxoides, HbsAg) } \\
\text { Clases y subclases de anticuerpos } \\
\text { (nefelometría, inmunoensayo) }\end{array}$ & Concentraciones normales de anticuerpos \\
\hline $\begin{array}{l}\text { Respuesta a } \\
\text { polisacáridos }\end{array}$ & $\begin{array}{l}\text { Inmunoensayo para IgG específica a antígenos } \\
\text { T-independientes (S. pneumoniae, } H \text {. influenzae) } \\
\text { Isohemaglutininas contra grupos sanguíneos A o B }\end{array}$ & $\begin{array}{l}\text { Título de lgG específica post-vacunación (o infección natural) } 4 \text { veces el valor basal } \\
\text { Título de isohemaglutininas } \geq 1 / 10\end{array}$ \\
\hline
\end{tabular}

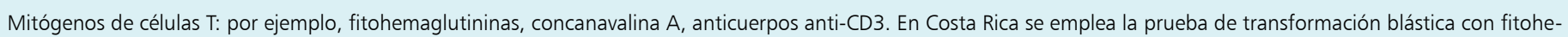

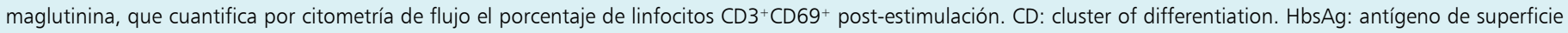
de hepatitis B. IgG: inmunoglobulina G. DS: desviación estándar. Adaptado de: ${ }^{34,46-48}$. 
ticuerpos no indica necesariamente que el paciente no haya desarrollado cierta inmunidad celular posterior a la inmunización o a la infección natural, a lo cual debe prestarse especial atención en el contexto de aplicación de vacunas víricas atenuadas a pacientes con hipogammaglobulinemia persistente ${ }^{52}$.

10. Pacientes receptores de trasplante que han recibido anticuerpos monoclonales (como por ejemplo anticuerpos anti-CD20 y anti-CD52) en los últimos seis meses antes del inicio de las inmunizaciones, desarrollan respuestas inmunes post-vacunales pobres ${ }^{53}$.

11. La inmunoglobulina intravenosa puede interferir con la respuesta antiviral porque puede contener anticuerpos contra sarampión, varicela y otros virus, por lo que las vacunas vivas atenuadas deben ser dadas como mínimo tres semanas antes o al menos ocho meses después de la última aplicación de inmunoglobulina ${ }^{54}$.

12. La presencia de infecciones leves no contraindica la aplicación de las vacunas. Sin embargo, la inmunización puede diferirse o post-ponerse en caso de enfermedad aguda o compromiso neurológico para evitar atribuir equivocadamente a la vacuna la aparición de un nuevo síntoma o la progresión de la sintomatología establecida ${ }^{51,55}$.

13. Toda vacuna se encuentra contraindicada en pacientes que hayan presentado reacción anafiláctica documentada a una dosis previa de la vacuna que se desea aplicar, a algún componente contenido en la vacuna en cuestión (por ejemplo, neomicina, estreptomicina o polimixina B), o a proteínas del huevo (presentes en la vacuna de virus de fiebre amarilla y en ciertas vacunas de influenza) $)^{51,56}$.

\section{Recomendaciones de vacunación para receptores de trasplante de células madre hematopoyéticas}

La población de pacientes receptores de trasplante de células madre hematopoyéticas se encuentra en continuo aumento como resultado del espectro cada vez más expandido de indicaciones para trasplante y la mejoría en la sobrevida. Las infecciones, incluyendo enfermedades inmunoprevenibles, constituyen una de las principales causas de muerte en estos pacientes, fundamentalmente después pero también antes del trasplante. Aunque existe evidencia limitada de que la vacunación previa al trasplante mejore la inmunidad después del procedimiento ${ }^{57}$, en teoría, la inmunización del receptor puede contribuir a garantizar una mejor protección durante el período más temprano consecutivo al trasplante, cuando la inmunosupresión es más profunda y las respuestas vacunales son más pobres ${ }^{49}$. Los candidatos a trasplante deberían recibir las vacunas indicadas para personas sanas basadas en edad, historia de inmunizaciones, factores individuales de riesgo e historia de exposición según los esquemas recomendados, si no se encuentran inmunosuprimidos y cuando el intervalo de inicio del acondicionamiento quimioterapéutico es $\geq$ a 4 semanas para vacunas vivas $\mathrm{y} \geq$ a 2 semanas para vacunas inactivadas ${ }^{45}$.

Pese a que existan algunas bases teóricas en cuanto a que la vacunación del donante de precursores hematopoyéticos en determinados casos constituya una estrategia que pueda mejorar la respuesta a vacunas del receptor (por ejemplo, aplicación de vacuna de hepatitis B al donante $)^{44}$, la vacunación del donante en beneficio del receptor no se recomienda y además es una práctica de poca aplicabilidad clínica dado que con frecuencia no se puede postergar el proceso de trasplante una vez que aparece el donante apropiado para el paciente. No obstante, se recomienda fuertemente que el donante de células madre hematopoyéticas tenga actualizado su esquema de inmunizaciones según los protocolos internacionales. La aplicación de vacunas atenuadas al donante debe evitarse en las cuatro semanas previas a la obtención o extracción de los precursores hematopoyéticos ${ }^{45}$. La necesidad de revacunación siempre debe ser evaluada individualmente ${ }^{58}$.

La Tabla 3 resume las recomendaciones internacionales de vacunación en pacientes que reciben trasplante alogénico de células madre hematopoyéticas ${ }^{44,45,50}$. Ante la carencia de estudios aleatorizados, controlados, respecto de las inmunizaciones en trasplante autólogo de células madre hematopoyéticas, trasplante de progenitores hematopoyéticos de cordón umbilical y en trasplantes realizados bajo regímenes de acondicionamiento quimioterapéutico no mieloablativo con intensidad reducida, se recomienda seguir las guías de vacunación disponibles para trasplante alogénico de células madre ${ }^{59}$.

\section{Vacunas inactivadas y toxoides}

\section{- Vacuna contra virus influenza}

Se recomienda la aplicación anual de la vacuna inactivada contra virus influenza en todos los receptores de trasplante, a partir de los seis meses post-trasplante y en los pacientes candidatos a trasplante de células hematopoyéticas (nivel de evidencia fuerte), dado que puede mejorar significativamente las tasas de seroprotección específica $^{60}$. Durante los brotes de influenza documentados por el ministerio o departamento de salud local, los pacientes que recibieron ya trasplante y que no han recibido aún la inmunización, deben recibir inmediatamente la vacuna si se encuentran al menos cuatro meses post-trasplante de células madre hematopoyéticas ${ }^{44,45}$. El antecedente de reacciones alérgicas de tipo cutáneo contra proteínas del huevo no contraindica la vacunación, pero en pacientes con historia de anafilaxia, las vacunas 


\begin{tabular}{|c|c|c|c|c|}
\hline Vacuna & $\begin{array}{l}\text { Inicio de la } \\
\text { vacunación }\end{array}$ & Esquema recomendado \pm & Solidez de la recomendación ${ }^{\circ}$ & Calidad de la evidencia ${ }^{+}$ \\
\hline Conjugada de S. pneumoniae & 3-6 meses & 3 dosis & Fuerte & Insuficiente \\
\hline 13-valente & & 4 dosis en presencia de GVHD crónico & Débil & Insuficiente \\
\hline $\begin{array}{l}\text { Polisacárida de S. pneumoniae } \\
\text { 23-valente }\end{array}$ & 12 meses & 1 dosis en ausencia de GVHD crónico & Fuerte & Insuficiente \\
\hline \multirow{2}{*}{$\begin{array}{l}\text { Conjugada de } N \text {. meningitidis } \\
\text { 4-valente }\end{array}$} & \multirow[t]{2}{*}{ 6-12 meses } & 2 dosis antes de 16 años & Fuerte & Insuficiente \\
\hline & & 1 refuerzo entre $16-18$ años & Fuerte & Insuficiente \\
\hline $\begin{array}{l}\text { Conjugada de } \mathrm{H} \text {. influenzae } \\
\text { tipo B }\end{array}$ & 6-12 meses & 3 dosis & Fuerte & Moderada \\
\hline \multirow{4}{*}{$\begin{array}{l}\text { Toxoide de difteria y tétanos } \\
\text { y vacuna acelular de } \\
\text { B. pertussis* }\end{array}$} & \multirow[t]{4}{*}{6 meses } & 3 dosis de DT & Fuerte & Insuficiente \\
\hline & & 3 dosis de DTaP & Débil & Insuficiente \\
\hline & & 1 dosis de Tdap y 2 dosis de DT & Débil & Moderada \\
\hline & & 1 dosis de Tdap y 2 dosis de $\mathrm{Td}$ & Débil & Insuficiente \\
\hline Inactivada de influenza & 6 meses & 1 dosis & Fuerte & Moderada \\
\hline Hepatitis A & 6 meses & 2 o 3 dosis & $\begin{array}{l}\text { Administración rutinaria no recomendada, eventual } \\
\text { beneficio en habitantes de países endémicos o } \\
\text { viajeros internacionales }\end{array}$ & $\begin{array}{l}\text { No hay estudios en } \\
\text { trasplantes }\end{array}$ \\
\hline \multirow[t]{2}{*}{ Hepatitis $B$ recombinante } & \multirow[t]{2}{*}{ 6-12 meses } & 3 dosis & Fuerte & Moderada \\
\hline & & $\begin{array}{l}\text { Repetir esquema si anti-HBs post- } \\
\text { vacunación menor a } 10 \mathrm{mUl} / \mathrm{mL}\end{array}$ & Fuerte & Insuficiente \\
\hline Inactivada de polio & 6-12 meses & 3 dosis & Fuerte & Moderada \\
\hline Papilomavirus humano & 6-12 meses & $\begin{array}{l}3 \text { dosis en adolescentes y adultos } \\
\text { hasta } 26 \text { años }\end{array}$ & Débil & Insuficiente \\
\hline $\begin{array}{l}\text { Atenuada de sarampión, } \\
\text { rubéola y parotiditis }\end{array}$ & 24 meses & $\begin{array}{l}2 \text { dosis en pacientes seronegativos } \\
\text { en ausencia de GVHD crónico o } \\
\text { supresión inmune }\end{array}$ & Fuerte & Insuficiente \\
\hline Atenuado de varicela & 24 meses & $\begin{array}{l}2 \text { dosis en pacientes seronegativos } \\
\text { en ausencia de GVHD crónico o } \\
\text { supresión inmune }\end{array}$ & Fuerte & Insuficiente \\
\hline
\end{tabular}

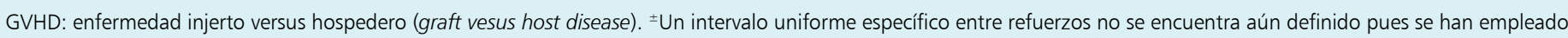

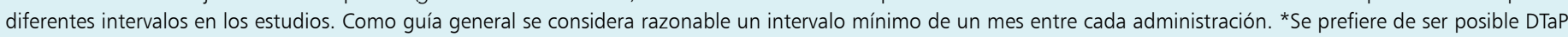

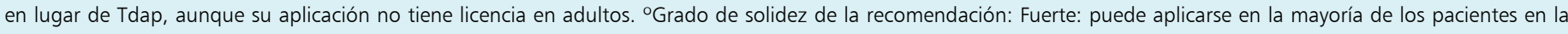

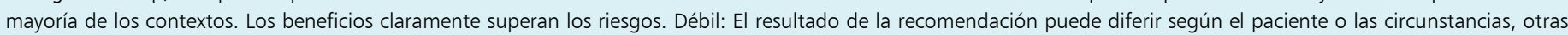

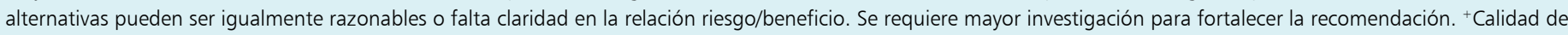

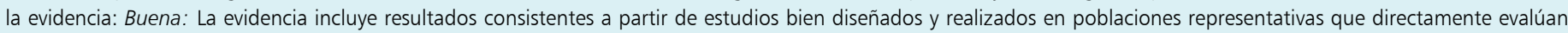

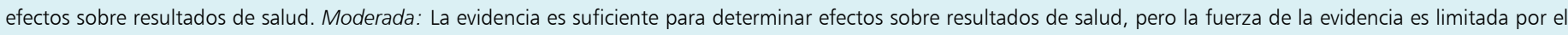

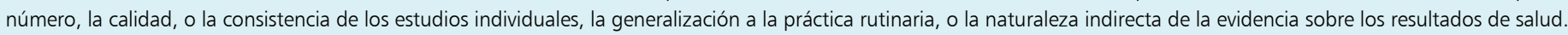

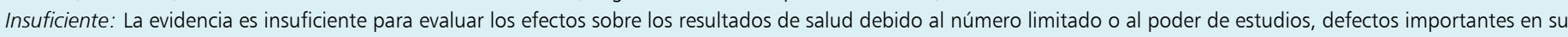
diseño o realización, inconsistencias en la secuencia de la evidencia, o falta de información sobre resultados de salud importantes ${ }^{44,45,84,112-115}$. 
trivalentes o tetravalentes inactivadas tradicionales están contraindicadas. Adultos con edades entre 18 a 49 años con antecedente de reacciones anafilácticas a proteínas del huevo, pueden recibir -en los países donde se disponga de ella- la vacuna recombinante de influenza (RIV), la cual no contiene proteínas de huevo. La vacuna viva intranasal debe evitarse en los receptores de trasplante ${ }^{61}$. El sistema de salud costarricense cuenta a nivel público sólo con la vacuna trivalente, que contiene dos cepas del virus tipo A (H1N1 y H3N2) y una cepa del virus B que causan brotes estacionales en el hemisferio sur ${ }^{62}$.

\section{- Vacuna contra virus hepatitis $B$}

Se recomienda administrar la vacuna contra hepatitis B en todos los pacientes receptores de trasplante de células madre hematopoyéticas que muestren pruebas serológicas negativas por HBsAg y anti-HBs y carga viral negativa por este virus, bajo un esquema de tres dosis que deben ser administradas seis a 12 meses posteriores al trasplante (nivel de evidencia fuerte) ${ }^{45}$.

En los sobrevivientes de trasplante de células hematopoyéticas se recomienda la medición regular de anticuerpos anti-HBsAg cada 4 o 5 años con el fin de monitorear el mantenimiento de concentraciones protectoras de estos anticuerpos y evaluar la necesidad de dosis de refuerzo adicionales $^{44,63}$. Se considera seroprotegida contra hepatitis $\mathrm{B}$ cualquier persona que alcance títulos de anticuerpos anti-HBsAg de al menos $10 \mathrm{UI} / \mathrm{mL}^{64}$. Si la concentración es menor, debe administrarse una segunda serie de tres dosis empleando una dosificación mayor $(40 \mu \mathrm{g})^{45}$.

La reactivación de la infección latente por hepatitis B, conocida como seroconversión reversa, es una complicación seria posterior al trasplante alogénico de células madre ${ }^{65}$, pero que también se ha descrito en trasplante autólogo ${ }^{66}$. En un estudio con 413 pacientes con $\mathrm{HBsAg}(+)$, que recibieron trasplante hematopoyético, la reactivación viral fue un evento común después del procedimiento ${ }^{67}$. Disrupciones en el balance entre la replicación viral y el control inmune contra el virus después del trasplante, pueden contribuir a la reactivación del virus, provocando inclusive falla hepática fulminante ${ }^{68-70}$. El uso de corticosteroides, la carencia de anticuerpos anti-HBs en el donante y la disminución de concentraciones séricas de anticuerpos anti-HBs y anti-HBc pueden predecir el riesgo de seroconversión reversa post-trasplante hematopoyéti$\mathrm{co}^{71}$. La posibilidad de reactivación viral es elevada, aun en receptores de donantes vacunados. Por estas razones, se recomienda inmunizar a todos los pacientes que exhiban positividad para HBsAg o anti-HBc, ya que la vacunación contra HBV puede reducir el riesgo de desarrollar dicha entidad $^{64,72,73}$. Así mismo, la administración profiláctica de antivirales en el período post-trasplante puede ser necesaria para evitar la reactivación ${ }^{67,74,75}$. Por otra parte, si el donador de células hematopoyéticas es portador de hepatitis B, se recomienda llevar a indetectable la carga viral del donador por medio de terapia antivírica antes de la donación. Previo al trasplante, es recomendable la inmunoprofilaxis del receptor con una dosis de la vacuna, seguida por la administración post-trasplante de inmunoglobulina específica contra hepatitis B si hay disponibilidad de este agente biológico. Además, se recomienda el inicio de profilaxis antivírica unos días antes del trasplante y continuar esta terapia por al menos tres meses si las cargas virales permanecen indetectables ${ }^{76-79}$.

\section{- Vacuna contra virus de hepatitis $A$}

La inmunización rutinaria contra hepatitis A en los pacientes que reciben trasplante de células madres hematopoyéticas no se contempla en las guías internacionales revisadas, aunque la aplicación de la vacuna inactivada no se encuentra contraindicada ${ }^{50,80}$. En la población adulta general, esta vacuna se recomienda en ciertos grupos de riesgo como trabajadores de instituciones médicas, estudiantes de ciencias de la salud, pacientes que requieren trasfusión recurrente de hemocomponentes, personas con enfermedades hepáticas crónicas, hombres homosexuales, habitantes de regiones endémicas, viajeros a zonas endémicas y adultos que desean reducir su posibilidad individual de contagio. El esquema de aplicación consiste en dos dosis separadas por un intervalo de 6 a 12 meses $^{81,82}$. En consideración a la eficacia de esta vacuna en personas sanas y las recomendaciones para inmunización de viajeros a países endémicos, es posible que los receptores de trasplante hematopoyético que vivan en zonas de transmisión o viajen a estas áreas puedan beneficiarse de la vacunación contra hepatitis $\mathrm{A}^{83,84}$.

- Vacuna conjugada contra H. influenzae tipo b (Hib)

La aplicación rutinaria de la vacuna contra Hib se halla recomendada en todos los receptores de trasplante de células madre hematopoyéticas, siguiendo un esquema de tres dosis en los primeros seis a 12 meses posteriores al trasplante ${ }^{45}$.

\section{- Vacunas contra S. pneumoniae}

El trasplante de células hematopoyéticas conlleva un riesgo elevado de desarrollar infecciones graves por $S$. pneumoniae, que constituyen una importante causa de morbilidad y mortalidad en este grupo de pacientes ${ }^{65}$. De hecho, la enfermedad neumocóccica es la infección bacteriana grave más común después de un trasplante de progenitores hematopoyéticos, siendo la neumonía la forma más frecuente de presentación. Estudios epidemiológicos han mostrado incidencias acumulativas de enfermedad invasora por $S$. pneumoniae (definida como neumonía, meningitis o bacteriemia) entre 1 y $10 \%$, con una media de presentación entre los 14 y 18 meses posteriores al trasplante $\mathrm{e}^{70,71}$. Otras investigaciones 
señalan incidencias de enfermedad invasora que oscilan entre 2,03 y 8,63 por cada 1.000 pacientes (la primera cifra corresponde a infecciones tempranas acontecidas en el primer mes post-trasplante, y la segunda cifra se refiere a infecciones tardías, documentadas después del día 100$)^{85,86}$. Si bien $S$. pneumoniae no es la causa más común de infección bacteriana en la fase neutropénica, la mortalidad debida a esta bacteria se reporta en alrededor de 20 a $30 \%$ de los casos durante dicho período, por lo que se le considera un agente importante de la fase de aplasia $^{87}$. Cerca de $40 \%$ de los adultos que reciben un trasplante alogénico y desarrollan infección invasora por $S$. pneumoniae llegan a requerir tratamiento en una unidad de medicina crítica, con una mortalidad que bordea el $30 \%{ }^{65}$. Diferentes estudios muestran que los receptores de trasplante hematopoyético tienen un riesgo 20 a 30 veces mayor de padecer infección neumocóccica invasora que la población general. Este riesgo parece ser más importante en los receptores de progenitores celulares de fuente alogénica, así como en aquellos pacientes que padecen de GVHD crónica, probablemente en relación con la inmunosupresión farmacológica que reciben para el tratamiento de esta entidad ${ }^{85,88}$. El método de trasplante también influye en el riesgo de infección neumocóccica, ya que se triplica al utilizar médula ósea completa, a diferencia de cuando se emplean células colectadas por aféresis (este último es el procedimiento más utilizado en pacientes adultos). Otros factores predisponentes a la infección por S. pneumoniae en receptores de trasplante hematopoyético son: disfuncionalidad esplénica inducida por irradiación corporal total y por el efecto inmunomodulador de la GVHD crónica, inmunosupresión con micofenolato de mofetilo (agente comúnmente empleado en el tratamiento de GVHD), hipogammaglobulinemia por daño acumulado sobre las células B y por eventual pérdida a través de mucosas, deficiencias transitorias de IgG2, defectos de opsonización (dada la capacidad limitada de producción de anticuerpos contra polisacáridos bacterianos y eventualmente, las fallas secundarias del sistema de complemento), ausencia de vacunación previa al trasplante y respuesta vacunal sub-óptima. Los pacientes sometidos a trasplante con hipoesplenia o asplenia definen un grupo particular de riesgo para infección neumocóccica invasora. Entre ambas condiciones, el factor que incide mayormente en la mortalidad es la asplenia anatómica ${ }^{65,87}$.

La vacuna neumocóccica más efectiva es la de tipo conjugado 13-valente (PCV13), pues al estimular una respuesta inmune $\mathrm{T}$-dependiente con generación de células B de memoria, posee un mayor potencial inmunogénico en pacientes inmunocomprometidos que las vacunas basadas en antígenos polisacáridos ${ }^{89}$. La vacuna polisacárida 23-valente (PPSV23) tiene una eficacia limitada durante el primer año posterior al trasplante, dado el tardío tiempo de regeneración de las respuestas celulares T y B y la inhabilidad de estos pacientes para establecer respuestas $\mathrm{T}$-independientes adecuadas ${ }^{90,91}$. Todo receptor de trasplante hematopoyético debe recibir tres dosis de PCV13 empezando en los primeros tres a seis meses después del trasplante. A los 12 meses del trasplante, podría proveerse una dosis de PPSV23 si el paciente no presenta GVHD crónica ${ }^{45}$. Aunque no existe consenso respecto de esta última indicación, la aplicación de PPSV23 como cuarta dosis vacunal después de la tercera dosis de PCV13 puede ser beneficiosa para amplificar la respuesta inmune obtenida con la vacuna conjugada ${ }^{44,61}$. Por otra parte, en un estudio reciente, la aplicación de cuatro dosis de PCV13 demostró también un aceptable perfil de seguridad, aunque este régimen se asoció con un incremento de reacciones locales y sistémicas ${ }^{88}$. En Costa Rica, se está implementando actualmente un protocolo de vacunación antineumocóccica para receptores de trasplante hematopoyético consistente en la aplicación de una dosis de PCV13, al menos dos semanas antes del trasplante, seguido de tres dosis de PCV13 tres a seis meses después del evento (esquema 0-2-4). En caso de evidencia de GVHD, dicho protocolo aconseja evitar inicialmente la vacunación y considerar un esquema de cuatro dosis (0-2-4-12) de PCV13 comenzando tres a seis meses después del inicio de la inmunosupresión ${ }^{92}$.

\section{- Vacuna contra Neisseria meningitidis}

La vacuna cuadrivalente conjugada contra $N$. meningitidis conteniendo los serogrupos A, C, W y Y (MenACWY oMCV4) es la vacuna preferida para la población general con edad $\leq$ a 55 años. En edades superiores a 55 años la única vacuna antimeningocóccica que tiene licencia es la polisacárida MPSV4. Ambas vacunas pueden prevenir cuatro serotipos de enfermedad meningocóccica, incluyendo dos de los tres tipos más comunes en los Estados Unidos de América y un tipo epidémico de África ${ }^{93}$. Se recomienda aplicar dos dosis de MCW4 seis a 12 meses después del trasplante a personas entre 11 y 18 años, con una dosis de refuerzo a los 16 a 18 años para quienes hayan recibido la dosis inicial entre los 11 y 15 años $^{45}$. En lo concerniente a $N$. meningitidis del serogrupo B, la Food and Drug Administration (FDA) aprobó en el año 2014 una vacuna para personas con edades entre 10 y 25 años. Para mayores de 26 años, su aplicación se considera "off-label" salvo en caso de brote epidémico, en el que la indicación se puede extender a cualquier edad. No existen aún recomendaciones respecto de esta vacuna en el contexto de trasplante o inmunosupresión ${ }^{94}$.

En cuanto a pacientes mayores de 18 años, no existen todavía indicaciones concretas de inmunización contra $N$. meningitidis ni consenso respecto de las dosis requeridas, pero la inmunización de pacientes inmunocomprometidos que no son portadores de infección por virus de inmunodeficiencia humana (VIH) debe evaluarse en el contexto 
individual, en caso de circulación endémica o brotes epidémicos de enfermedad meningocóccica causada por los serogrupos A, C, W y Y ${ }^{44,94}$.

Es importante mencionar que aunque $N$. meningitidis no es un agente infeccioso frecuentemente reportado como causante de infecciones graves en pacientes sometidos a trasplante, existe una realidad epidemiológica latente en América del Sur, principalmente en Chile, país donde se reportó un cambio en la epidemiología local de la bacteria desde el año 2012, que afectó tanto a niños pequeños como a adultos jóvenes. De esta forma, cuando se presenta un brote de meningitis por $N$. meningitidis, es imprescindible realizar la caracterización del agente causal y considerar, con base en los factores de riesgo conocidos de infección invasora meningocóccica (asplenia funcional o anatómica, deficiencia de properdina, deficiencia de componentes terminales de la vía del complemento, infección respiratoria por virus de influenza, edad, exposición al humo de tabaco, hacinamiento, bajo nivel socio-económico) ${ }^{95}$, si los receptores de trasplante serían candidatos a vacunarse con MCV4 cuando la realidad epidemiológica así lo justifique. En Chile, el aumento de casos de enfermedad meningocóccica invasora registrados en el 2012 fue originado por el serogrupo $\mathrm{W}$, lo que obligó a las entidades de salud de esa nación a desarrollar un programa de vacunación de la población con mayor riesgo ${ }^{96,97}$.

\section{- Toxoides de Clostridium tetani, Corynebacterium} diphtheriae y vacuna acelular de Bordetella pertussis

Tres dosis de una vacuna contra tétanos y difteria deben ser administradas seis meses después del trasplante. Debe aplicarse posteriormente un refuerzo al menos cada 10 años, ya que se ha demostrado que la inmunidad humoral contra tétanos y difteria en receptores de trasplante que han recibido el esquema completo de revacunación persiste alrededor de nueve años ${ }^{42,98}$. Para pacientes $\geq \mathrm{de}$ siete años, debe considerarse la aplicación de tres dosis de la vacuna combinada DTaP (tétanos, difteria y pertussis acelular). Alternativamente, puede ofrecerse una dosis de una vacuna con pertussis acelular (Tdap) seguida de 2 dosis de toxoide diftérico y tetánico (DT o Td) ${ }^{45}$. La vacuna DTaP que se administra en la infancia contiene mayor carga antigénica que la Tdap del adulto, la que es menos inmunogénica. Por tanto de ser posible, se recomienda inmunizar los pacientes que reciben trasplante de células madres hematopoyéticas con DTaP de manera inicial ${ }^{44}$. En Costa Rica, esta vacuna no cuenta con registro sanitario para su aplicación en adultos.

\section{- Vacuna inactivada contra poliovirus}

Se recomienda la aplicación de esta vacuna en los receptores de trasplante de células madre hematopoyéticas en un esquema de tres dosis después de seis a 12 meses post trasplante ${ }^{45,80}$.

\section{- Vacuna contra virus de papiloma humano (VPH)}

Las recomendaciones actuales consideran la administración de esta vacuna en esquema de tres dosis en todos los receptores de trasplante hematopoyético cuyas edades se encuentren entre 11 y 26 años, seis a 12 meses después del trasplante. Los varones deben recibir la vacuna que contiene cuatro serotipos $(\mathrm{VPH} 4)^{45}$. Recientemente se ha incluido a los esquemas internacionales de inmunizaciones la vacuna nonavalente de VPH (9vVPH), que puede ser utilizada en la vacunación rutinaria de hombres y mujeres ${ }^{99}$.

\section{Vacunas virales vivas atenuadas}

\section{- Vacuna contra sarampión, rubéola y parotiditis}

Debe considerarse la administración de la vacuna a los 24 meses del trasplante si el paciente tiene una adecuada competencia inmunológica demostrada mediante los análisis previamente mencionados ${ }^{36,50}$.

\section{- Vacuna contra virus de fiebre amarilla}

Se puede considerar la administración de la vacuna contra la fiebre amarilla a los 24 meses post-trasplante en los casos en que esté indicada (habitante de zona endémica o viajero a un área con riesgo de transmisión), y si se ha demostrado que el paciente tiene una adecuada competencia inmunológica. En América, los países endémicos para este virus son Argentina, Bolivia, Brasil, Colombia, Ecuador, Guyana, Guyana Francesa, Panamá, Paraguay, Perú, Surinam, Trinidad y Tobago y Venezuela ${ }^{62,100,101}$.

\section{- Vacunas contra virus varicela y herpes zoster}

La infección y reactivación por el virus varicela zoster afecta a receptores de trasplante hematopoyético en los primeros 12 meses post-trasplante, lo que hace necesaria la administración temprana de profilaxis antiviral ${ }^{102,103}$. Entre los factores de riesgo para el desarrollo de infección por virus varicela se han reportado la edad, irradiación corporal total, concomitancia de GVHD crónica e inicio tardío de agentes antivirales profilácticos ${ }^{104}$. Pese a lo anterior, hasta la fecha la experiencia con vacunas de este virus en receptores de trasplante es insuficiente, por lo cual la inmunización con vacunas vivas de varicela o de herpes zoster se encuentra contraindicada a menos de que se haya demostrado una reconstitución completa del sistema inmune a los 24 meses del trasplante, en ausencia tanto de terapia inmunosupresora como de enfermedad injerto contra hospedero ${ }^{52,105}$. La evidencia aún es deficitaria en relación con la utilidad de la vacunación precoz. Un estudio reciente en el que se inmunizó receptores de trasplante autólogo a partir de los 4,5 meses del trasplante evidenció que la aplicación de la vacuna atenuada de varicela fue segura en ese grupo de pacientes pero pobremente inmunogénica ${ }^{106}$. La recomendación para pacientes sero- 
negativos que cumplan con los requisitos mencionados es que reciban una serie de dos inmunizaciones, y en caso de haber recibido inmunoglobulina intravenosa, la reciban 8 a 11 meses tras la última dosis de este tratamiento inmunomodulador. Los candidatos no inmunodeficientes a trasplante deben recibir la vacuna de varicela en un régimen de dos dosis si hay suficiente tiempo previo al procedimiento, si no se encuentran inmunosuprimidos y al menos cuatro semanas antes del inicio de la terapia de acondicionamiento. Se recomienda la inmunización del personal de salud y de todos los contactos cercanos del paciente que no hayan presentado la infección natural o sean seronegativos para varicela ${ }^{45}$.

En lo que respecta a la vacuna de herpes zoster, ésta contiene una concentración 14 veces mayor de cepa OKA que la vacuna de varicela, por lo que está contraindicada, tanto en trasplante hematopoyético como de órganos sólidos ${ }^{107}$. Sin embargo, es importante tomar en consideración que los adultos mayores tienen una incidencia de enfermedad por herpes zoster 10 veces mayor que la población en general ${ }^{106}$. En este sentido, los autores recomiendan que si se contempla la inmunización en pacientes receptores de trasplante mayores de 50 años, la vacuna debe sólo ser administrada si el paciente es seronegativo y posee una adecuada competencia inmunológica. Dos estudios intervencionales recientes reportaron seguridad en la administración de vacuna de herpes zoster en receptores de trasplante hematopoyético dos años después del procedimiento, aunque no evaluaron la tasa de seroconversión ${ }^{108,109}$. En la actualidad se estudian dos nuevas vacunas inactivadas de virus herpes zoster que podrían ser alternativas interesantes para pacientes inmunocomprometidos. La primera es una vacuna de varicela inactivada por calor que ha sido probada en receptores de trasplante de células madre hematopoyéticas, demostrando seguridad y un incremento de la inmunidad celular antiviral específica ${ }^{110}$. La segunda es una vacuna recombinante que igualmente ha sido evaluada en el contexto del trasplante hematopoyético en un estudio clínico de fase 2 . Dicha vacuna inactivada conteniendo glucoproteína E del virus de varicela zoster, demostró respuestas inmunes robustas en pacientes receptores de trasplante autólogo de células madre hematopoyéticas con un aceptable perfil de seguridad y podría aplicarse 50 a 70 días después del trasplante ${ }^{111}$.

\section{- Otras vacunas vivas atenuadas}

Vacunas vivas como la vacuna contra poliovirus oral, Vibrio cholerae, fiebre tifoidea (Vivotif $®$ ) y bacilo de Calmette-Guerin (BCG), se encuentran contraindicadas en los receptores de trasplante de células madre hematopoyéticas. Vacunas inactivadas contra fiebre tifoidea podrían ser consideradas en situaciones epidemiológicas especiales $^{44,52}$.

\section{Vacunación de familiares, contactos cercanos y trabajadores del área de salud en relación con receptores de trasplante de células madre hematopoyéticas}

Antes del trasplante de células madre hematopoyéticas, todos los familiares y contactos cercanos del paciente deben tener actualizado su esquema personal de vacunaciones ${ }^{58}$.

La vacuna de varicela se halla altamente recomendada en todas las personas seronegativas $\geq$ de 12 meses que vayan a mantener una relación cercana con un receptor de trasplante, salvo si se encuentran en período de gestación o bajo inmunosupresión (nivel de evidencia AIII) ${ }^{112}$. La inmunización contra varicela del conviviente debe ejecutarse antes de que el paciente inicie el tratamiento inmunosupresor o el proceso de trasplante y posteriormente la persona vacunada debe evitar el contacto con el paciente durante seis semanas. En caso de presentarse erupción cutánea a raíz de la vacunación, se debe evitar el contacto con el paciente durante el tiempo que ésta permanezca. Cuando el familiar tiene 13 años o más, debe recibir dos dosis de la vacuna, ya que son necesarias dos dosis para incidir en los brotes. La aplicación de una sola dosis sólo incide en la mortalidad y morbilidad individual ${ }^{41}$.

Se considera esencial la aplicación anual de la vacuna inactivada contra virus de influenza en todos los familiares de los pacientes que reciben trasplante y en el personal de salud que los atiende (nivel de evidencia AII) ${ }^{45}$.

La inmunización contra el virus de hepatitis A, sarampión, rubéola y parotiditis se encuentra recomendada de manera rutinaria en toda persona mayor de un año de edad que conviva con pacientes receptores de trasplante ${ }^{44}$, incluyendo personal de salud. La vacuna de hepatitis B se halla igualmente recomendada en los contactos cercanos del paciente receptor de trasplante ${ }^{41}$.

Se recomienda la vacunación contra $B$. pertussis en toda persona que tenga contacto cercano con pacientes receptores de trasplante, inclusive personal de salud ${ }^{44,58}$.

La administración de la vacuna contra rotavirus no está contraindicada en los contactos cercanos del receptor de trasplante ${ }^{44,52}$.

La vacuna contra polio en su presentación viva tipo Sabin (administrada por vía oral) está contraindicada en contactos de pacientes que reciban trasplante de células madre ${ }^{41}$.

\section{Conclusiones}

La prevención de las infecciones en pacientes que han recibido trasplante de células madre hematopoyéticas es primordial para disminuir y evitar la excesiva morbimortalidad derivada de la inmunosupresión farmacológica prolongada y de las complicaciones inherentes al tras- 
plante (alteración de la microbiota, mucositis, infecciones virales crónicas inmunosupresoras, enfermedad injerto versus hospedero, etc.). La inmunoprofilaxis constituye una vía muy importante de prevención de enfermedades infecciosas posteriores al trasplante, dado que en el período inmediato al evento acontece una pérdida casi completa de la memoria inmunológica contra infecciones inmunoprevenibles en la mayor parte de los casos. Pequeños estudios han demostrado que para la mayoría de esas infecciones los pacientes pueden montar respuestas inmunes suficientes con ayuda de las inmunizaciones. Las pandemias de virus influenza, los recientes brotes de parotiditis y sarampión en Europa, el incremento de infecciones por $B$. pertussis y el aumento de resistencia en cepas de $S$. pneumoniae han fortalecido la necesidad de una revacunación efectiva en estos pacientes. Siguiendo las recomendaciones de vacunación en pacientes receptores de trasplante, los beneficios superan los riesgos de la intervención. Junto con la vacunación del receptor es necesario que los trabajadores de salud y las personas que mantienen contacto cercano con pacientes sometidos a trasplante se encuentren también adecuadamente inmunizados.

Si bien es cierto las guías internacionales de manejo de pacientes trasplantados recomiendan fuertemente la inmunización de todos los receptores bajo esquemas cada vez mejor definidos, el momento adecuado de inicio de la vacunación permanece siendo un motivo de debate. Muchos pacientes con impedimentos inmunitarios no son capaces de establecer respuestas eficaces y protectoras posterior a la inmunización activa. Por esta razón, es preponderante determinar el nivel de competencia inmunitaria posterior al trasplante, tanto para estratificar el riesgo de infección como para definir el momento óptimo de la inmunización en cada caso. Esto es particularmente relevante cuando se pretende sopesar la conveniencia de aplicación de vacunas vivas atenuadas. Los métodos de evaluación de las reacciones inmunológicas no se encuentran estandarizados aún en pacientes que reciben trasplantes. Se sugiere el uso de métodos sencillos que valoran en forma indirecta la calidad de la respuesta inmune adaptativa, como son los retos inmunológicos con vacunas inactivadas con ulterior medición de la respuesta serológica. En este contexto, son necesarios estudios prospectivos que mejoren la calidad de la evidencia que defina el momento más indicado de inmunización de donantes y receptores de trasplante. De igual manera, es necesario diseñar estudios que identifiquen marcadores biológicos para predecir el establecimiento de respuestas adecuadas y durables a las vacunas.

\section{Resumen}

El presente artículo revisa las recomendaciones actuales para la inmunización de pacientes adultos que han recibido trasplante de células madre hematopoyéticas, procedimiento común en la terapia de muchas patologías hematológicas y defectos congénitos del sistema inmune. Los pacientes que reciben este tipo de tratamiento son más susceptibles a infecciones inmunoprevenibles que la población general debido a la pérdida de la inmunidad protectora tanto humoral como celular con posterioridad al trasplante. De esta manera, la revacunación de los receptores de trasplante representa una estrategia importante para reducir la morbilidad y mortalidad asociadas con esas enfermedades. Sin embargo, se conoce poco sobre la duración y magnitud de la respuesta inmunológica generada por las vacunas en esta población. Además, aunque existen guías internacionales consensuadas en inmunoprofilaxis post-trasplante, frecuentemente ocurren desviaciones en las prácticas recomendadas por múltiples motivos, incluyendo la no disponibilidad de ciertas vacunas en algunos sistemas de salud. Factores como la intensidad de la inmunosupresión farmacológica, el régimen mieloablativo empleado, la administración de anticuerpos monoclonales y policlonales, la duración de la fase neutropénica en el período posterior al trasplante y la presencia de enfermedad injerto versus hospedero (graft-versus-host disease, GVHD) pueden influenciar la respuesta inmunitaria y establecer consideraciones especiales para ciertos agentes como es el caso de las vacunas compuestas por virus vivos atenuados. Estas condiciones contribuyen a que el momento oportuno de inicio de las inmunizaciones en los receptores de trasplante aún no se encuentre bien definido. Se requieren más estudios específicos acerca de los mecanismos inmunológicos subyacentes durante los estados de inmunocompromiso para entender mejor la inmunogenicidad y seguridad de las vacunas existentes en dichos contextos. El desarrollo de vacunas innovadoras puede también inducir avances en la terapia post-trasplante. 


\section{Referencias bibliográficas}

1.- Welniak L A, Blazar B R, Murphy W J. Immunobiology of allogeneic hematopoietic stem cell transplantation. Annu Rev Immunol 2007; 25 (1): 139-70.

2.- Gaziev J, Lucarelli G. Stem cell transplantation and gene therapy for hemoglobinopathies. Curr Hematol Rep 2005; 4 (2): 126-31.

3.- Witherspoon R, Storb R, Ochs H, Fluornoy N, Kopecky K, Sullivan K, et al. Recovery of antibody production in human allogeneic marrow graft recipients: influence of time posttransplantation, the presence or absence of chronic graft-versus-host disease, and antithymocyte globulin treatment. Blood 1981; 58 (2): 360-8.

4.- Paulin T, Ringdén O, Lönnqvist B. Faster immunological recovery after bone marrow transplantation in patients without cytomegalovirus infection. Transplantation 1985; 39 (4): 377-84.

5.- Storek J, Dawson M A, Storer B, StevensAyers T, Maloney D G, Marr K A, et al. Immune reconstitution after allogeneic marrow transplantation compared with blood stem cell transplantation. Blood 2001; 97 (11): 3380-9.

6.- Lum L, Munn N, Schanfield M, Storb R. The detection of specific antibody formation to recall antigens after human bone marrow transplantation. Blood 1986; 67 (3): 582-7.

7.- Ambrosino D M, Molrine D C. Critical appraisal of immunization strategies for prevention of infection in the compromised host. Hematol/Oncol Clin North Am 1993; 7 (5): 1027-50.

8.- Lum L. The kinetics of immune reconstitution after human marrow transplantation. Blood 1987; 69 (2): 369-80.

9.- Charbonnier A, Sainty D, Faucher C, Arnoulet C, Chabannon C, Blaise D. Immune reconstitution after blood cell transplantation. Hematol Cell Ther 1997; 39 (5): 261-4.

10.- Laurenti L, Sica S, Salutari P, Rutella S, Serafini R, D'Onofrio G, et al. Assessment of hematological and immunological function during long-term follow-up after peripheral blood stem cell transplantation. Haematologica 1998; 83 (2): 138-42.

11.- Kernan N A, Bartsch G, Ash R C, Beatty P G, Champlin R, Filipovich A, et al. Analysis of 462 transplantations from unrelated donors facilitated by the National Marrow Donor Program. N Engl J Med 1993; 328 (9): 593-602.

12.- Small T N, Papadopoulos E B, Boulad F, Black P, Castro-Malaspina H, Childs B H, et al. Comparison of immune reconstitution after unrelated and related T-cell-depleted bone marrow transplantation: effect of patient age and donor leukocyte infusions. Blood 1999; 93 (2): 467-80.
13.- Thomson B G, Robertson K A, Gowan D, Heilman D, Broxmeyer H E, Emanuel D, et al. Analysis of engraftment, graft-versushost disease, and immune recovery following unrelated donor cord blood transplantation. Blood 2000; 96 (8): 2703-11.

14.- Ruggeri A, Peffault de Latour R, Carmagnat M, Clave E, Douay C, Larghero J, et al. Outcomes, infections, and immune reconstitution after double cord blood transplantation in patients with high-risk hematological diseases. Transplant Infect Dis 2011; 13 (5): 456-65.

15.- Jacobson C A, Turki A T, McDonough S M, Stevenson K E, Kim H T, Kao G, et al. Immune reconstitution after double umbilical cord blood stem cell transplantation: comparison with unrelated peripheral blood stem cell transplantation. Biol Blood Marrow Transp 2012; 18 (4): 565-74.

16.- Scarselli A, Di Cesare S, Capponi C, Cascioli S, Romiti M L, Di Matteo G, et al. Longitudinal evaluation of immune reconstitution and B-cell function after hematopoietic cell transplantation for primary immunodeficiency. J Clin Immunol 2015; 35 (4): 373-83.

17.- Sica S, Laurenti L, Sorà F, Menichella G, Rumi C, Leone $\mathrm{G}$, et al. Immune reconstitution following transplantation of autologous peripheral CD34+ cells. Acta Haematol 2001; 105 (3): 179-87.

18.- Talmadge J E, Reed E, Ino K, Kessinger A, Kuszynski C, Heimann D, et al. Rapid immunologic reconstitution following transplantation with mobilized peripheral blood stem cells as compared to bone marrow. Bone Marrow Transplant 1997; 19 (2): 161-72.

19.- Petersen S L, Ryder L P, Bjork P, Madsen H O, Heilmann C, Jacobsen N, et al. A comparison of T-, B- and NK-cell reconstitution following conventional or nonmyeloablative conditioning and transplantation with bone marrow or peripheral blood stem cells from human leucocyte antigen identical sibling donors. Bone Marrow Transplant 2003; 32 (1): 65-72.

20.- Mehta R S, Rezvani K. Immune reconstitution post allogeneic transplant and the impact of immune recovery on the risk of infection. Virulence 2016; 6: 1-16.

21.- Hokland M, Jacobsen N, Ellegaard J, Hokland P. Natural killer function following allogeneic bone marrow transplantation. Very early reemergence but strong dependence of cytomegalovirus infection. Transplantation 1988; 45 (6): 1080-4.

22.- Brahmi Z, Hommel-Berrey G, Smith F, Thomson B. NK cells recover early and mediate cytotoxicity via perforin/granzyme and Fas/FasL pathways in umbilical cord blood recipients. Human Immunol 2001; 62 (8): 782-90.

23.- Mackall C L, Fleisher T A, Brown M R, Andrich M P, Chen C C, Feuerstein I M, et al.
Distinctions between CD8+ and CD4+ T-cell regenerative pathways result in prolonged T-cell subset imbalance after intensive chemotherapy. Blood 1997; 89 (10): 3700-7.

24.- Berger M, Figari O, Bruno B, Raiola A, Dominietto A, Fiorone M, et al. Lymphocyte subsets recovery following allogeneic bone marrow transplantation (BMT): $\mathrm{CD} 4+$ cell count and transplant-related mortality. Bone Marrow Transplant 2008; 41 (1): 55-62.

25.- Geddes M, Storek J. Immune reconstitution following hematopoietic stem-cell transplantation. Best Practice \& Res Clin Haematol 2007; 20 (2): 329-48.

26.- Storek J, Saxon A. Reconstitution of B cell immunity following bone marrow transplantation. Bone Marrow Transplant 1992; 9 (6): 395-408.

27.- Storek J, Wells D, Dawson M A, Storer B, Maloney D G. Factors influencing B lymphopoiesis after allogeneic hematopoietic cell transplantation. Blood 2001; 98 (2): 489-91.

28.- Lewin S R, Heller G, Zhang L, Rodrigues E, Skulsky E, van den Brink M R M, et al. Direct evidence for new T-cell generation by patients after either T-cell-depleted or unmodified allogeneic hematopoietic stem cell transplantations. Blood 2002; 100 (6): 2235-42.

29.- Roux E, Dumont-Girard F, Starobinski M, Siegrist C-A, Helg C, Chapuis B, et al. Recovery of immune reactivity after T-cell-depleted bone marrow transplantation depends on thymic activity. Blood 2000; 96 (6): 2299-303.

30.- Storek J, Joseph A, Dawson M A, Douek D C, Storer B, Maloney D G. Factors influencing T-lymphopoiesis after allogeneic hematopoietic cell transplantation. Transplantation 2002; 73 (7): 1154-8

31.- Ochs L, Shu X, Miller J, Enright H, Wagner J, Filipovich A, et al. Late infections after allogeneic bone marrow transplantations: comparison of incidence in related and unrelated donor transplant recipients. Blood 1995; 86 (10): 3979-86.

32.- Bosch M, Khan F M, Storek J. Immune reconstitution after hematopoietic cell transplantation. Cur Opin Hematol 2012; 19 (4): 324-35.

33.- Orange J S, Ballow M, Stiehm E R, Ballas Z K, Chinen J, De La Morena M, et al. Use and interpretation of diagnostic vaccination in primary immunodeficiency: A working group report of the Basic and Clinical Immunology Interest Section of the American Academy of Allergy, Asthma \& Immunology. J Allergy Clin Immunol 2012; 130 (3): S1-S24.

34.- García Martínez J, Santos-Díez L, Dopazo L. Diagnóstico de las inmunodeficiencias primarias. Protoc Diagn Ther Pediatr 2013; 1: 81-92. 
35.- Looney R J, Diamond B, Holers M, Levesque M, Moreland L, Nahm M, et al. Guidelines for assessing immunocompetency in clinical trials for autoimmune diseases. Clin Immunol (Orlando, Fla.) 2007; 123 (3): 235-43.

36.- Kawamura K, Yamazaki R, Akahoshi Y, Nakano H, Ugai T, Wada H, et al. Evaluation of the immune status against measles, mumps, and rubella in adult allogeneic hematopoietic stem cell transplantation recipients. Hematology 2015; 20 (2): 77-82.

37.- Oliveira J B, Fleisher T A. Laboratory evaluation of primary immunodeficiencies. $\mathrm{J}$ Allergy Clin Immunol 2010; 125 (2 Suppl 2): S297-S305.

38.- Greenberg R N, Gurtman A, Frenck R W, Strout C, Jansen K U, Trammel J, et al. Sequential administration of 13-valent pneumococcal conjugate vaccine and 23 -valent pneumococcal polysaccharide vaccine in pneumococcal vaccine-naïve adults 60-64 years of age. Vaccine 2014; 32 (20): 2364-74.

39.- Cordonnier C, Labopin M, Jansen K U, Pride M, Chesnel V, Bonnet E, et al. Relationship between IgG titers and opsonocytophagocytic activity of antipneumococcal antibodies after immunization with the 7-valent conjugate vaccine in allogeneic stem cell transplant. Bone Marrow Transplant 2010; 45 (9): 1423-6.

40.- Romero-Steiner S, Frasch C E, Carlone G, Fleck R A, Goldblatt D, Nahm M H. Use of opsonophagocytosis for serological evaluation of pneumococcal vaccines. Clin Vaccine Immunol 2006; 13 (2): 165-9.

41.- Guidelines for preventing opportunistic infections among hematopoietic stem cell transplant recipients. MMWR Recomm Rep 2000; 49 (Rr-10): 1-125, ce1-7.

42.- Hammarstrom V, Pauksen K, Bjorkstrand B, Simonsson B, Oberg G, Ljungman P. Tetanus immunity in autologous bone marrow and blood stem cell transplant recipients. Bone Marrow Transplant 1998; 22 (1): 67.

43.- Roberts M M, To L B, Gillis D, Mundy J, Rawling C, Ng K, et al. Immune reconstitution following peripheral blood stem cell transplantation, autologous bone marrow transplantation and allogeneic bone marrow transplantation. Bone Marrow Transplant 1993; 12 (5): 469-75

44.- Tomblyn M, Chiller T, Einsele H, Gress R, Sepkowitz K, Storek J, et al. Guidelines for Preventing Infectious Complications among Hematopoietic Cell Transplantation Recipients: A global perspective. Biol Blood Marrow Transplant 2009; 15 (10): 1143-238.

45.- Rubin L G, Levin M J, Ljungman P, Davies E G, Avery R, Tomblyn M, et al. Executive Summary: 2013 IDSA Clinical Practice Guideline for Vaccination of the
Immunocompromised Host. Clin Infect Dis 2014; 58 (3): 309-18.

46.- Galicchio M, Ornani A. Guías de manejo: vacunas en pacientes con inmunodeficiencias primarias. Arch Argent Pediatr 2010; 108 (5): 454-64.

47.- Maino V C, Suni M A, Ruitenberg J J. Rapid flow cytometric method for measuring lymphocyte subset activation. Cytometry 1995 20 (2): 127-33.

48.- Simms P E, Ellis T M. Utility of flow cytometric detection of CD69 expression as a rapid method for determining poly- and oligoclonal lymphocyte activation. Clin Diagn Laboratory Immunol 1996; 3 (3): 301-4.

49.- L'Huillier A G, Kumar D. Immunizations in solid organ and hematopoeitic stem cell transplant patients: A comprehensive review. Hum Vaccin Immunother 2015; 11 (12): 2852-63.

50.- Johnston B L, Conly J M. Immunization for bone marrow transplant recipients. Can J Infect Dis 2002; 13 (6): 353-7.

51.- Contraindications and Precautions to Commonly Used Vaccines in Adults. National Center for Immunization and Respiratory Diseases. http:// www.cdc.gov/vaccines/schedules/hcp/imz/adultcontraindications.html (accedido el 7 de abril de 2016)

52.- L'Huillier A G, Posfay-Barbe K M. Live viral vaccines in transplanted patients. Swiss Med Wkly 2014; (144): w14005.

53.- Issa N C, Baden L R. Current issues in vaccines for adult patients with hematologic malignancies. J Nat Comprehen Cancer Network 2012; 10 (11): 1447-54.

54.- Recommended intervals between administration of immune globulin preparations and measles-or varicella-containing vaccine in Epidemiology and Prevention of VaccinePreventable DiseasesCenters for Disease Control and Prevention Vol. 13th. https://www. cdc.gov/vaccines/pubs/pinkbook/downloads/ appendices/a/mmr_ig.pdf (accedido el $15 \mathrm{de}$ julio de 2016).

55.- General recommendations on immunizationrecommendations of the Advisory Committee on Immunization Practices (ACIP). MMWR Recomm Rep 2011; 60 (2): 1-64.

56.- Clark A T, Skypala I, Leech S C, Ewan P W, Dugué P, Brathwaite N. et al. British Society for Allergy and Clinical Immunology Guidelines for the Management of Egg Allergy. Clin Experimen Allergy 2010; 40 (8): 1116-29.

57.- Harris A E, Styczynski J, Bodge M, Mohty M, Savani B N, Ljungman P. Pretransplant vaccinations in allogeneic stem cell transplantation donors and recipients: an often-missed opportunity for immunoprotection[quest]. Bone Marrow Transplant 2015; 50 (7): 899-903.

58.- Ariza-Heredia E J, Gulbis A M, Stolar K R,
Kebriaei P, Shah D P, McConn K K, et al. Vaccination guidelines after hematopoietic stem cell transplantation: practitioners' knowledge, attitudes, and gap between guidelines and clinical practice. Transpl Infect Dis 2014; 16 (6): 878-86.

59.- Meerveld-Eggink A, van der Velden A M T, Ossenkoppele G J, van de Loosdrecht A A, Biesma D H, Rijkers G T. Antibody response to polysaccharide conjugate vaccines after nonmyeloablative allogeneic stem cell transplantation. Biol Blood Marrow Transplant 2009; 15 (12): 1523-30.

60.- Ambati A, Boas L S V, Ljungman P, Testa L, de Oliveira J F, Aoun M, et al. Evaluation of pretransplant influenza vaccination in hematopoietic SCT: a randomized prospective study. Bone Marrow Transplant 2015; 50 (6): 858-64.

61.- Kim D K, Bridges C B, Harriman K H. Advisory Committee on Immunization Practices Recommended Immunization Schedule for Adults Aged 19 Years or Older: United States, 2015* Recommended Adult Immunization Schedule: United States, 2015. Ann Intern Med 2015; 162 (3): 214-23.

62.- Zúñiga Morales V, Sánchez Alfaro A N, Fernández Delgado N, Ramírez Fernández H, Salazar H, Arroba Tijerino R. Norma nacional de vacunación - Ministerio de Salud, Costa Rica. 2013; 1-128.

63.- Idilman R, Arat M. Evaluation and management of hepatitis B virus infection in hematopoietic stem cell transplantation: before and after transplantation. Expert Rev Anti Infect Ther 2011; 9 (8): 641-52.

64.- Takahata M, Hashino S, Onozawa M, Shigematsu A, Sugita J, Fujimoto K, et al. Hepatitis B virus (HBV) reverse seroconversion (RS) can be prevented even in non-responders to hepatitis B vaccine after allogeneic stem cell transplantation: long-term analysis of intervention in RS with vaccine for patients with previous HBV infection. Transpl Infect Dis 2014; 16 (5): 797-801.

65.- Torda A, Chong Q, Lee A, Chen S, Dodds A, Greenwood M, et al. Invasive pneumococcal disease following adult allogeneic hematopoietic stem cell transplantation. Transpl Infect Dis 2014; 16 (5): 751-9.

66.- Ma S-y, Lau G K K, Cheng V C C, Liang R. Hepatitis $\mathrm{B}$ reactivation in patients positive for hepatitis B surface antigen undergoing autologous hematopoietic cell transplantation. Leukemia \& Lymphoma 2003; 44 (8): 1281-5.

67.- Nakamoto S, Kanda T, Nakaseko C, Sakaida E, Ohwada C, Takeuchi M, et al. Reactivation of hepatitis B virus in hematopoietic stem cell transplant recipients in Japan: efficacy of nucleos(t)ide analogues for prevention and treatment. Intern J Molecular Sci 2014; 15 (11): 21455 . 
68.- Caselitz M, Link H, Hein R, Maschek H, Böker K, Poliwoda H, et al. Hepatitis B associated liver failure following bone marrow transplantation. J Hepatol 1997; 27 (3): 572-7.

69.- McIvor C, Morton J, Bryant A, Cooksley W G, Durrant S, Walker N. Fatal reactivation of precore mutant hepatitis B virus associated with fibrosing cholestatic hepatitis after bone marrow transplantation. Ann Inter Med 1994; 121 (4): 274-5.

70.- Lau G K, Liang R, Chiu E K, Lee C K, Lam S K. Hepatic events after bone marrow transplantation in patients with hepatitis B infection: a case controlled study. Bone Marrow Transplant 1997; 19 (8): 795-9.

71.- Goyama S, Kanda Y, Nannya Y, Kawazu M, Takeshita M, Niino M, et al. Reverse seroconversion of hepatitis B virus after hematopoietic stem cell transplantation. Leuk Lymphoma 2002; 43 (11): 2159-63.

72.- Knöll A, Boehm S, Hahn J, Holler E, Jilg W. Long-term surveillance of haematopoietic stem cell recipients with resolved hepatitis B: high risk of viral reactivation even in a recipient with a vaccinated donor. J Viral Hepat 2007; 14 (7): 478-83.

73.- Onozawa M, Hashino S, Darmanin S, Okada K, Morita R, Takahata M, et al. HB vaccination in the prevention of viral reactivation in allogeneic hematopoietic stem cell transplantation recipients with previous $\mathrm{HBV}$ infection. Biol Blood Marrow Transplant 2008; 14 (11): 1226-30.

74.- Tavil B, Kuşkonmaz B, Kasem M, Demir H, Çetin M, Uçkan D. Hepatitis B immunoglobulin in combination with lamivudine for prevention of hepatitis $B$ virus reactivation in children undergoing bone marrow transplantation. Pediatr Transplant 2006; 10 (8): 966-9.

75.- Shang J, Wang H, Sun J, Fan Z, Huang F, Zhang Y, et al. A comparison of lamivudine vs entecavir for prophylaxis of hepatitis B virus reactivation in allogeneic hematopoietic stem cell transplantation recipients: a singleinstitutional experience. Bone Marrow Transplant 2016; 51 (4): 581-6.

76.- Sobhonslidsuk A, Ungkanont A. A prophylactic approach for bone marrow transplantation from a hepatitis B surface antigen-positive donor. World J Gastroenterol: WJG 2007; 13 (7): $1138-40$.

77.- Locasciulli A, Alberti A, Bandini G, Polchi P, Arcese W, Alessandrino P, et al. Allogeneic bone marrow transplantation from $\mathrm{HBsAg}+$ donors: a multicenter study from the Gruppo Italiano Trapianto di Midollo Osseo (GITMO). Blood 1995; 86 (8): 3236-40.

78.- Lau G K K, Lie A K W, Kwong Y L, Lee C K, Hou J, Lau Y L, et al. A case-controlled study on the use of HBsAg-positive donors for allogeneic hematopoietic cell transplantation. Blood 2000; 96 (2): $452-8$.

79.- Hui C-k, Lie A, Au W-y, Ma S-y, Leung Y-H, Zhang H-Y, et al. Effectiveness of prophylactic anti-HBV therapy in allogeneic hematopoietic stem cell transplantation with HBsAg positive donors. Am J Transplant 2005; 5 (6): $1437-45$

80.- Hilgendorf I, Freund M, Jilg W, Einsele H, Gea-Banacloche J, Greinix H, et al. Vaccination of allogeneic haematopoietic stem cell transplant recipients: Report from the International Consensus Conference on Clinical Practice in chronic GVHD. Vaccine 2011; 29 (16): 2825-33.

81.- Fiore A E, Wasley A, Bell B P. Prevention of hepatitis A through active or passive immunization: recommendations of the Advisory Committee on Immunization Practices (ACIP). MMWR Recomm Rep 2006; 55 (Rr-7): $1-23$.

82.- Craig T, Pürsün E A, Bork K, Bowen T, Boysen H, Farkas H, et al. WAO Guidelines for the Management of Hereditary Angioedema. World Allergy Org J 2012; 5 (12): 1-18.

83.- Machado C M. Reimmunization after bone marrow transplantation: current recommendations and perspectives. Braz J Med Biol Res 2004; 37: 151-8.

84.- Canadian Immunization Guide-Part 3 Vaccination of Specific Populations. Public Health Agency of Canada. http://www.phacaspc.gc.ca/publicat/cig-gci/p03-07-eng.php. (accedido el 7 de abril de 2016).

85.- Kulkarni S, Powles R, Treleaven J, Riley U, Singhal S, Horton C, et al. Chronic graft versus host disease is associated with long-term risk for pneumococcal infections in recipients of bone marrow transplants. Blood 2000; 95 (12): 3683-6.

86.- Youssef S, Rodríguez G, Rolston K V, Champlin R E, Raad II, Safdar A. Streptococcus pneumoniae infections in 47 hematopoietic stem cell transplantation recipients: clinical characteristics of infections and vaccinebreakthrough infections, 1989-2005. Medicine 2007; 86 (2): 69-77.

87.- Engelhard D, Cordonnier C, Shaw P J, Parkalli T, Guenther C, Martino R, et al. Early and late invasive pneumococcal infection following stem cell transplantation: a European bone marrow transplantation survey. $\mathrm{Br} \mathrm{J}$ Haematol 2002; 117 (2): 444-50.

88.- Cordonnier C, Ljungman P, Juergens C, Maertens J, Selleslag D, Sundaraiyer V, et al. Immunogenicity, safety, and tolerability of 13-valent pneumococcal conjugate vaccine followed by 23 -valent pneumococcal polysaccharide vaccine in recipients of allogeneic hematopoietic stem cell transplant aged $\geq 2$ years: an open-label study. Clin Infect Dis 2015; 61 (3): 313-23.
89.- Clutterbuck E A, Lazarus R, Yu L-M, Bowman J, Bateman E A L, Diggle L, et al. Pneumococcal conjugate and plain polysaccharide vaccines have divergent effects on antigen-specific B cells. J Infect Dis 2012; 205 (9): 1408-16.

90.- D'Orsogna L J, Wright M P, Krueger R G, McKinnon E J, Buffery S I, Witt C S, et al. Allogeneic hematopoietic stem cell transplantation recipients have defects of both switched and IgM memory B cells. Biol Blood Marrow Transplant 2009; 15 (7): 795-803.

91.- Kumar D, Chen MH, Welsh B, Siegal D, Cobos I, Messner HA, et al. A randomized, double-blind trial of pneumococcal vaccination in adult allogeneic stem cell transplant donors and recipients. Clin Infect Dis 2007; 45 (12): 1576-82.

92.- Arroba Tijerino R, Machado Cruz V. Lineamientos para vacunación antineumocócica. en preparación edn (Ministerio de Salud de Costa Rica, 2016).

93.- Meningococcal ACWY Vaccines (MenACWY and MPSV4) VIS. National Center for Immunization and Respiratory Diseases. http:// www.cdc.gov/vaccines/hcp/vis/vis-statements/ mening.html (accedido el 5 de julio de 2016).

94.- Recommended Adult Immunization Schedule U.S. 2016. Centers for Disease Control and Prevention. http://www.cdc.gov/vaccines/ schedules/downloads/adult/adult-schedule.pdf. (accedido el 7 de abril de 2016).

95.- Soult Rubio J A, Muñoz Sáez M. Enfermedad meningocócica invasora. Anales Pediatr 2005; (62): 297-303.

96.- Valenzuela M T, Moreno G, Vaquero A, Seoane M, Hormazábal J C, Bertoglia M P, et al. Emergencia de la cepa W135 causante de enfermedad meningocócica invasora en Chile 2012. Rev Med Chile 2013; 141: 959-67.

97.- Araya P, Fernández J, Del Canto F, Seoane M, Ibarz-Pavón A B, Barra G, et al. Neisseria meningitidis ST-11 clonal complex, Chile 2012. Emerg Infect Dis 2015; 21 (2): 339-41.

98.- S Škovránková J, Petráš M. Persistence of humoral immunity to tetanus and diphtheria in hematopoietic stem cell transplant recipients after post-transplant immunization. Pediatr Blood Cancer 2012; 59 (5): 908-13.

99.- Petrosky E, Bocchini J A, Jr., Hariri S, Chesson H, Curtis C R, Saraiya M, et al. Use of 9-valent human papillomavirus (HPV) vaccine: updated HPV vaccination recommendations of the advisory committee on immunization practices. MMWR Morb Mortal Wkly Rep 2015; 64 (11): 300-4

100.-Fiebre Amarilla. Organización Panamericana de la Salud. http://www.paho.org/worldhealth-day-2014/wp-content/uploads/2014/04/ Yellow-fever-esp.pdf (accedido el 16 de julio de 2016). 
101.-Fiebre Amarilla. Organización Mundial de la Salud. http://www.who.int/mediacentre/ factsheets/fs100/es/ (accedido el 16 de julio de 2016).

102.-Han C S, Miller W, Haake R, Weisdorf D. Varicella zoster infection after bone marrow transplantation: incidence, risk factors and complications. Bone Marrow Transplant 1994; 13 (3): 277-83.

103.-Koc Y, Miller K B, Schenkein D P, Griffith J, Akhtar M, DesJardin J, et al. Varicella zoster virus infections following allogeneic bone marrow transplantation: Frequency, risk factors, and clinical outcome. Biol Blood Marrow Transplant 2000; 6 (1): 44-9.

104.-Umezawa Y, Kakihana K, Oshikawa G, Kobayashi T, Doki N, Sakamaki H, et al. Clinical features and risk factors for developing varicella zoster virus dissemination following hematopoietic stem cell transplantation. Transplant Infect Dis 2014; 16 (2): 195-202.

105.-Socié G, Ritz J. Current issues in chronic graft-versus-host disease. Blood 2014; 124 (3): 374-84.

106.-Sasadeusz J, Prince H M, Schwarer A, Szer J, Stork A, Bock H L, et al. Immunogenicity and safety of a two-dose live attenuated varicella vaccine given to adults following autologous hematopoietic stem cell transplantation. Transplant Infect Dis 2014; 16 (6): 1024-31.

107.-Verolet C, Posfay-Barbe K. Live virus vaccines in transplantation: friend or Foe? Curr Infect Dis Rep 2015; 17 (4): 1-11.

108.-Naidus E, Damon L, Schwartz B S, Breed C, Liu C. Experience with use of Zostavax ${ }^{\circledR}$ in patients with hematologic malignancy and hematopoietic cell transplant recipients. Am J Hematol 2012; 87 (1): 123-5.

109.-Issa N C, Marty F M, Leblebjian H, Galar A, Shea M M, Antin J H, et al. Live attenuated varicella-zoster vaccine in hematopoietic stem cell transplantation recipients. Biol Blood Marrow Transplant 2014; 20 (2): 285-7.

110.-Mullane K M, Winston D J, Wertheim M S, Betts R F, Poretz D M, Camacho L H, et al. Safety and immunogenicity of heat-treated zoster vaccine (ZVHT) in immunocompromised adults. J Infect Dis 2013; 208 (9): 1375-85.

111.-Stadtmauer E A, Sullivan K M, Marty F M, Dadwal S S, Papanicolaou G A, Shea T C, et al. A phase 1/2 study of an adjuvanted varicellazoster virus subunit vaccine in autologous hematopoietic cell transplant recipients. Blood 2014; 124 (19): 2921-9.

112.-Campins M, Martínez X, Cossio Y, Bayas J M. Protocolo de vacunación de pacientes trasplantados de órganos hematopoyéticos. SEMPSPH. http://www. sempsph.com/images/stories/recursos/pdf/ protocolos/2012/Protocolo_vacunacion organo_hematopoyetico $\% \overline{20}$.pdf (accedido el 4 de julio de 2016).

113.-Majhail N S, Rizzo J D, Lee S J, Aljurf M, Atsuta Y, Bonfim C, et al. Recommended screening and preventive practices for longterm survivors after hematopoietic cell transplantation. Bone Marrow Transplant 2012; 47 (3): 337-41.

114.-Bonheví P, Gentile A, Gonzáles Ayada S, López E, Yedlin P. Vacunación en Huéspedes Especiales. Lineamientos Técnicos Actualización. (Ministerio de Salud, Argentina, 2014).

115.-Marzo Castillejo M, Viana Zulaica C. Calidad de la evidencia y grado de recomendación. in Guías Clínicas 2007fisterra.com Vol. 7 1-14. http://www.fisterra.com/guias2/fmc/sintesis.pdf. (accedido el 16 de julio de 2016). 